\title{
Film Tari; \\ Sebuah Hibridasi Seni Tari, Teknologi Sinema, dan Media Baru
}

\author{
Deny Tri Ardianto ${ }^{1}$, Bedjo Riyanto ${ }^{2}$ \\ ${ }^{1,2}$ Desain Komunikasi Visual, Universitas Sebelas Maret, Surakarta, Indonesia \\ 1'denytri@staff.uns.ac.id
}

Film tari telah memiliki sejarah panjang seiring kelahiran film di dunia. Namun demikian kehadirannya tidak serta merta disadari oleh masyarakat dunia. Film tari berkembang dalam sepi di tengah riuhnya film-film popular yang merajai bioskop-bioskop komersial. Kini film tari seakan ingin menampilkan eksistensinya melalui pemutaran dan diskusi di beberapa event festival film tari, pemutaran di kampus-kampus, serta komunitas kesenian. Semakin banyak ruang-ruang pemutaran turut menggiatkan para pembuat film dan koreografer untuk semakin produktif memproduksi film tari. Ditunjang perkembangan teknologi sinema yang secara nominal semakin terjangkau masyarakat, produksi dan distribusi film tari semakin meningkat. Hal tersebut yang menjadi salah satu penanda bangkitnya film tari di dunia. Namun bagaimanakah perkembangan film tari di Indonesia? Potensi film tari berkembang di Indonesia sangat terbuka lebar, karena Indonesia kaya akan tari tradisional yang siap untuk dieksplorasi berhibridasi dengan film/video. Menggunakan pendekatan kualitatif deskriptif, kajian dari tulisan ini diharapkan bisa memberikan wawasan bagaimana perkembangan seni tari dan seni film berkolaborasi dengan beragam dukungan teknologi sinema dan media baru berkembang di Indonesia.

Kata kunci: film tari, hibridasi, sinema

Proses Review : 1 - 28 Januari 2020, Dinyatakan Lolos: 10 Februari 2020 


\section{PENDAHULUAN}

Di tahun 2017 seorang koreografer muda dari Solo, Dwi Windarti, menciptakan film tari berjudul Mendut, The Untold Story (2017). Sebuah film tari dalam format digital video berwarna hitam putih. Mendut, The Untold Story bercerita tentang sisi rapuh Roro Mendut dibalik penampilannya yang selalu terlihat berani, kuat, dan periang. Mendut, The Untold Story merupakan salah satu film yang turut memeriahkan gelaran Bandung Dance Film Festival 2017, salah satu dari rangkaian program acara Seni Bandung bertajuk The Collaboration Art Event, tanggal 25 September hingga 25 Oktober 2017. Selain Mendut, The Untold Story, film-film tari dari beberapa negara juga turut ambil bagian antara lain, KALAP! karya Deny Ardianto (Indonesia), Anastasis dan Cerita-Cerita Sebelumnya karya kolaborasi Sardono W. Kusumo dan Faozan Rizal (Indonesia), Panelhoenan karya Ami Skanberg Dahlstedt (Swedia), Human Passion karya Budi Arifianto (Indonesia), Hyperscape karya Marco Gerris dan Wilko Gello (Belanda), Tanah Air Udara Aku Kamu dan Malam karya Yola Yulfianti (Indonesia) dan masih banyak lagi.

Program Bandung Dance Film Festival 2017 merupakan salah satu event yang memberikan ruang untuk berinteraksi dan berdiskusi antara para pembuat film tari melalui karya film tarinya dengan masyarakat. Beberapa program pemutaran film tari yang sebelum dan setelahnyanya pernah diselenggarakan antara lain Dance on Screen Festival 2005, Dance and Film dalam Indonesian Dance Festival 2012, Film Screening dalam Indonesian Dance Festival 2016, Film Screening dalam Jakarta Dance Carnival 20162019, Imajitari-International Dance Film Festival 20182019, dan pemutaran-pemutaran gerilya atau bergaya indie yang dilakukan oleh sutradara, koreografer ataupun komunitas penggiat film tari.

Penyelenggaraan event festival atau pemutaran film tari di Indonesia jika dibandingkan dengan negara lain, terutama di kawasan Amerika dan Eropa, masih jauh tertinggal. Manajer program Dance and Film dalam gelaran IDF 2012, Adi Wicaksono mengatakan bahwa film tari memang belum begitu dikenal oleh masyarakat, terbukti dengan sepinya penonton film di segmen Dance and Film, di hari pertama pemutaran segmen ini hanya dihadiri 30 orang penonton (Indriasari, 2012). Melihat isi diskusi dari beberapa kegiatan di atas, seperti Dance on Screen Festival 2005, masih diwarnai seputar pengertian dan batasan dari film tari, bahkan selang 12 tahun kemudian di event Bandung Dance Film Festival 2017, diskusi publik masih menanyakan hal yang sama. Hal tersebut menunjukkan bahwa film tari belum begitu dikenal luas di Indonesia.

Namun demikian, meski film tari belum dikenal secara luas di Indonesia, beberapa pembuat film tari terus berekplorasi memproduksi dan mengembangkan film tari, dan mencoba mengirimkan karya-karyanya ke festival-festival film tari di beberapa negara. Selain format pemutaran film seperti festival pada umumnya, festival-festival tersebut menawarkan beragam format festival yang berbeda, ada yang dalam format Virtual Reality (VR), online streaming, co-working project, dan festival yang khusus untuk film tari yang diproduksi menggunakan mobilephone. Berkembangnya media teknologi untuk produksi dan banyaknya alternatif media baru sebagai media presentasi meningkatkan kreatifitas para kreator film tari untuk bereksperimen dengan beragam teknologi sinema yang saat ini berkembang pesat. Namun sejauh mana para penggiat film tari di Indonesia mengeksplorasi teknologi video atau film dan media baru dalam membuat dan mendistribusikan karyanya?

\section{METODE PENELITIAN}

Penelitian ini merupakan penelitian deskriptif kualitatif yang kerap digunakan untuk menganalisis fenomena, peristiwa, aktivitas sosial, sikap, kepercayaan, persepsi, pemikiran orang secara individual maupun kelompok. Metode penelitian ini memanfaatkan data kualitatif dan dijabarkan secara deskriptif (Sukmadinata, 2010). Melalui pendekatan deskriptif peneliti bermaksud untuk memahami fenomena tentang apa yang dialami oleh subjek penelitian misalnya perilaku, persepsi, motivasi, tindakan secara holistik, dengan mendeskripsikannya dalam bentuk kata-kata dan bahasa, pada suatu konteks khusus yang alamiah dan dengan memanfaatkan berbagai metode alamiah (Moleong, 2005)

Penelitian ini menggunakan teknik wawancara, observasi, dan dokumentasi untuk mengumpulkan data. Wawancara dengan subjek penelitian yang terdiri dari penggiat film tari (pembuat film tari dan penyelenggara event atau festival film tari), serta observasi langsung berdasar pengalaman pribadi penulis dalam mengikuti beberapa festival film tari baik di dalam dan luar negeri akan di fokuskan pada pemanfaatan media digital atau teknologi media baru dalam memproduksi karya film tari serta pola pendistribusian karya-karya film tari tersebut ke masyarakat luas. Selain itu, dukungan data dari dokumentasi berupa karyakarya film tari baik produksi karya anak bangsa dan dari luar negeri digunakan untuk melengkapi hasil wawancara dan observasi langsung di lapangan.

\section{PEMBAHASAN}

\section{Hibridasi Seni Film dan Seni Tari}

Film tari pada dasarnya merupakan penggabungan koreografi tarian dengan kerja alat produksi film, yaitu kamera. Kamera akan berusaha menangkap momen estetis dari tarian yang didesain untuk keperluan kamera, dan hasilnya akan diproyeksikan kembali dalam format yang telah tersusun sedemikian rupa. Artinya, film tari adalah sebuah koreografi tari yang dibuat hanya untuk keperluan kamera film atau video. Selain itu juga bisa dimaknai 
sebagai suatu interpretasi koreografi tarian melalui film atau video yang hasil hibridasi-nya tidak dapat dinikmati secara terpisah, baik dari sisi estetika tarinya saja atau pun sinematografinya saja (Ardianto, 2014). Menurut David Rousseve, seorang profesor dalam bidang koreografi dan performance dari University of California, Los Angeles (UCLA), berangkat dari perspektif dia sebagai seorang sutradara dan koreografer, film tari adalah sebuah koreografi tari yang dibuat khusus untuk keperluan kamera, bukan untuk kebutuhan panggung pertunjukan (Rousseve, 2012). Artinya, sejauh film atau video itu bukan sebagai sebuah bentuk dokumentasi tarian, kemungkinan masuk kategori film tari masih cukup terbuka.

Film tari (dancefilm) bukanlah satu-satunya istilah untuk genre film ini. Beberapa sinematografer atau filmmaker dan koreografer memiliki istilah masing-masing untuk mendiskripsikan kekaryaan mereka, antara lain: Dance for the Camera, Video Dance, Dance Film, Dance in Film, Choreocinema, Screendance, Cinedance, dan Dance Movie (Ardianto, 2014: 15). Namun pada prinsipnya, perbedaan istilah itu tidak turut mempengaruhi pengertian film tari itu sendiri. Saat ini film tari hadir dalam beberapa format atau kategori, antara lain dalam kemasan film cerita pendek, panjang, eksperimental, animasi, dan film dokumenter. Bahkan dalam perayaannya yang ke-10 pada tahun 2018 di Helsinki, Finlandia, Loikka Dance Film Festival menerima karya film tari dalam bentuk Virtual Reality (VR) $360^{\circ}$, dan kini beberapa festival lain sudah mengikuti jejaknya.

\section{Teknologi Film dan Media Baru}

Sebelum era kamera digital hadir, para pembuat film menggunakan kamera seluloid. Kamera film (begitu tipe kamera ini banyak disebut) merupakan kamera yang menggunakan bahan dasar (pita) seluloid berukuran super8, $16 \mathrm{~mm}, 35 \mathrm{~mm}$, dan $65 \mathrm{~mm}$, disesuaikan dengan tipe kamera itu sendiri. Dimulai pada era film bisu diakhir 1800-1930-an, untuk pertama kalinya Thomas Edison melalui Edison Manufacturing Co dengan sutradara William K.L. Dickson dan sinematografer William Heise, memfilmkan kegiatan orang yang sedang menari, antara lain potongan dokumentasi Ruth Dennis yang sedang menari skirt dance (1894) dan dokumentasi tarian Annabelle Moore dalam Annabelle Butterfly Dance (1894). Selain itu Edison Manufacturing Co dalam film Imperial Japanese Dance (1894), mendokumentasikan pertunjukan tari tradisional Jepang, Mikado, ditarikan oleh tiga penari dengan mengenakan kostum tradisional Jepang (Ardianto, 2014: 21).

Tidak lama setelah Edison Manufacturing Co memproduksi film Imperial Japanese Dance, muncul film-film dengan karakter yang sama, diantaranya besutan Lumiere Brothers dan Peter Elfeldt berjudul Danse Serpentine (1896) ditarikan oleh Loie Fuller, juga rekaman tari dari Royal Danish Ballet saat membawakan koreografi karya- karya August Bournonville (1902), dan Fire Dance (1906) yang menampilkan kembali Loie Fuller (Ardianto, 2014: 22). Dapat dikatakan, keterkaitan film dan tari pada masa itu masih bersifat dokumentatif. Kamera hanya mendokumentasikan pertunjukan tari di dalam studio atau di panggung.

Tahun 1930-1950an teknologi audio dalam film mulai berkembang dan era film bersuara hadir di dunia. Saat itu Hollywood belum terbiasa dengan produksi film bersuara. Sutradara dan koreografer tari kemudian berkolaborasi mengembangkan struktur baru dalam film, yaitu berupa pertunjukan tari sebagai pendukung film musikal. Hasilnya, dengan bantuan mata kamera, gerakan tari bahkan ekspresi penari dapat ditangkap secara detail. Apalagi dengan pergerakan kamera yang cukup aktif, seperti panning, tilting, dan zooming, menciptakan impresi baru dalam dunia tari melalui film komersial dengan genre musikal (Mitoma, 2002: 12). Pada era itu fungsi tari di dalam film lebih diposisikan sebagai bumbu pelengkap dan dekorasi dalam penceritaan film atau drama musikal, baik dengan obyek live shot ataupun dengan menggabungan tari dengan animasi, seperti dalam film Anchors Aweigh (1945), Easter Parade (1948), dan The 5,000 Fingers of Dr. T. (1953).

Film tari mulai berkembang di Amerika pada tahun 1960an, salah satu pemrakarsa gerakan experimental modern dance film adalah Merce Cunningham. Menurut Cunningham, kamera bekerja sebagai sebuah instrument kreatif yang membingkai, dan menstruktur pandangan serta rasa dari tarian, sehingga memunculkan emosional yang berbeda dibandingkan pertunjukan di atas panggung atau dalam sebuah konser. Koreografer Amerika lain yang juga aktif bekerja dengan medium film adalah Yvonne Rainer. Yvonne Rainer sejak 1967 telah menghasilkan 12 karya film, beberapa film cerita panjang dan termasuk film pendek tanpa suara untuk konsep pertunjukan multimedia seperti Filmed Choreographic Exercises (1967) (Wolff, 2015). Latar belakang Yvonne sebagai seorang koreografer sangat terlihat dalam film-filmnya yang menitikberatkan pada koreografi-koreografi tari dan gesture tubuh (Brannigan, 2006).

Sejak SONY Co. memperkenalkan teknologi portable video camera pertama pada tahun 1960an, dunia gambar hidup (motion picture) mengalami revolusi besar-besaran. Teknologi video relatif murah dibandingkan dengan menggunakan pita film (selluloid). Selain tanpa melalui proses cuci cetak untuk melihat hasilnya, gambar dan suara dapat langsung direkam bersamaan tanpa melakukan synchronizing. Kepraktisan yang dimiliki medium ini membuat para koreografer dan filmmaker merasa bahwa video merupakan teknologi yang cukup ideal untuk membantu proses kreatif mereka, seperti untuk pendokumentasian tari (baik latihan maupun pementasan), serta penciptaan koreografi dalam mengkreasi film tari (Rosenberg, 2000: 2). 
Kemunculan teknologi video juga berdampak pada perkembangan film tari di dunia pertelevisian. Di Amerika, program-program yang berkaitan dengan film tari (dance film) atau dance for the camera semakin meningkat. Stasiun-stasiun televisi berlomba-lomba memproduksi program bertajuk tari-tarian sebagai bagian program acara seni dan kebudayaan, baik dalam format dokumentasi, maupun film documenter (Venza, 2002: 5). Kemunculan teknologi video memacu peningkatan jumlah karya-karya film tari diperiode ini. Hingga akhirnya tahun 1971, Dance Films Association (DFA) yang bertempat di New York menyelenggarakan Dance on Camera Festival untuk pertama kalinya. Dance on Camera Festival diadakan setiap tahun hingga sekarang. Selain menyelenggarakan festival, DFA juga mengorganisir (tour) pemutaran dan festival karyakarya film tari di seluruh dunia.

Selain di wilayah dokumentasi, film dokumenter, film eksperimental, kemunculan teknologi video juga berpengaruh dalam perkembangan film tari di ranah komersial. Hal itu didukung dengan kemunculan Music Television (MTV) tahun 1980an. Banyak musisi dunia dalam pembuatan video klipnya menggunakan tari misalnya: Michael Jackson dalam Thriller, Beat It dan Billie Jean (1982/1983) dan Madonna dalam Material Girl (1985). Saat ini dapat dikatakan separuh dari video klip musik di dunia diisi dengan tari-tarian, terutama gaya tari modern, hip hop, break dance dan sebagainya.

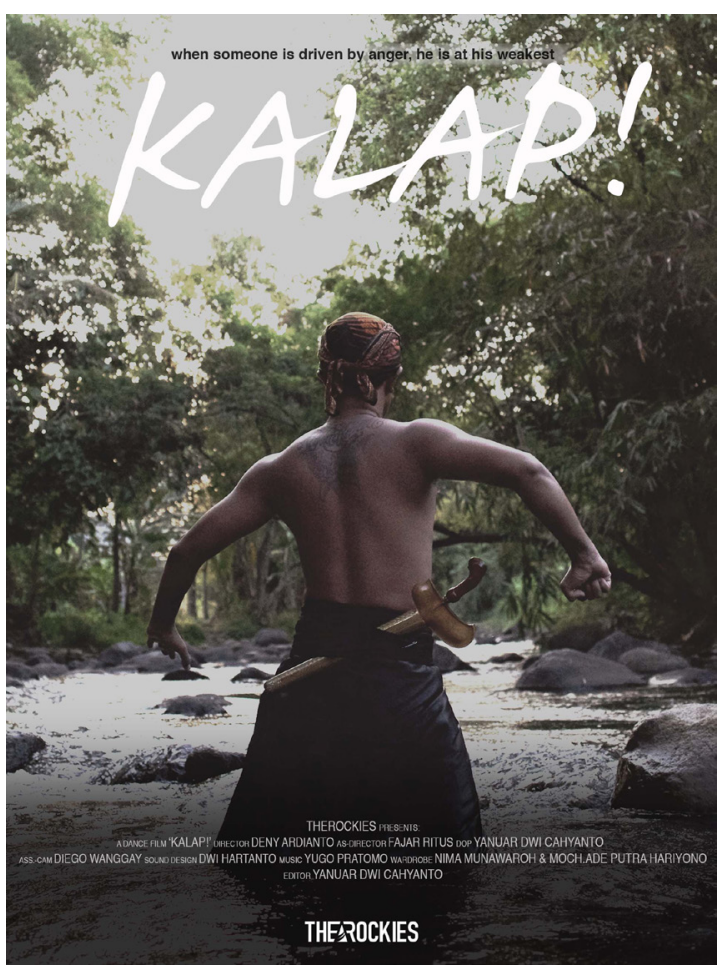

Gambar 1. Poster film tari KALAP! (2017), dengan sutradara Deny Ardianto

(Sumber: dokumentasi pribadi)
Sejak tahun 1980an, video analog secara perlahan bertransformasi ke format digital, dan seiring kemajuan internet, teknologi digital semakin berkembang pesat di tahun 2000an. Saat ponsel Blackbarry booming di Indonesia tahun 2009an, koreografer Yola Yulfianti menggunakan ponsel Blackbarry untuk merekam video tarinya. Dengan mengikatkan di tubuh penari, kamera pada ponsel tersebut merekam setiap gerak tubuh penari. Saat ini, banyak koreografer dan pembuat film menggunakan kamera GoPro yang dilekatkan pada tubuh penari untuk membangun adegan-adegan tari agar lebih terlihat personal. Dalam film terbarunya yang berjudul $K A L A P$ !, penulis juga memanfaatkan teknologi drone camera untuk merekam landscape dan adegan-adegan dramatis dari udara.

Teknologi digital tidak hanya membantu dalam produksi film, pola konsumsi dan distribusi filmpun menjadi lebih efektif. Saat ini konsep menonton film tidak lagi harus pergi ke gedung bioskop atau di depan layar televisi, orang dapat menyaksikannya dari beragam jenis portable gadget seperti i-phone, sellular phone, dan komputer tablet. Media baru telah menggantikan cara manusia mengkonsumsi sebuah tayangan. Perangkat keras yang awalnya hanya untuk tujuan komunikasi kini menjadi bagian dari keseharian dalam menikmati hiburan dan bahkan dengan sifat interaktifitasnya, media membuat penonton menjadi bagian langsung dari hiburan itu sendiri. Seperti yang disampaikan Neuman dalam Croteau dan Hoynes (2003), bahwa saat ini kita menyaksikan evolusi melalui jaringan komunikasi audio, video, dan teks elektronik yang saling berhubungan secara universal, yang mengaburkan perbedaan antara komunikasi antarpribadi, massa, dan pihak-pihak swasta. Neuman beranggapan media baru akan mengubah jarak geografis, meningkatkan komunikasi dalam skala besar, kecepatan komunikasi, terbangunnya sistem komunikasi interaktif yang dulu terpisah-pisah kini bahkan akan saling tumpang tindih dan interkoneksi.

Hal inilah yang kemudian menginspirasi para pembuat film dan koreografer untuk mengkreasi karya film tarinya agar dapat diakses melalui internet dan bahkan bersifat interaktif. Beberapa koreografer di Amerika dan Eropa juga telah memanfaatkan teknologi Virtual Reality (VR) $360^{\circ}$ dalam menghadirkan kekaryaannya. Melalui teknologi tersebut, dimensi ruang tidak lagi menjadi batasan karena penonton seolah-olah langsung mengalami kejadian yang sebenarnya dan terlihat nyata.

Shut in Dance Film Fest, sebuah festival film tari online atau daring (dalam jaringan) di USA juga menawarkan berkarya kolaboratif dengan cara penari mengirimkan secara daring footage tariannya yang kemudian akan diseleksi kesesuaiannya dengan proyek yang akan dibuat. Jika lolos seleksi, penari tersebut akan didukung oleh tim yang telah disediakan oleh pihak festival yang antara lain terdiri dari seorang creative director, musisi, koreografer, dan pembuat film. Selain arahan dari tim tersebut, festival 
juga akan mengirimkan tutorial atau panduan bagaimana penari tersebut dapat merekam gerakannya menggunakan smartphone dengan kualitas hasil gambar terbaik. Setelah itu hasil video tersebut dikirim ke tim festival dan difinalisasi menjadi sebuah film tari yang utuh. Kerja dengan sistem remote atau jarak jauh tersebut tentu saja merupakan sesuatu yang baru di wilayah film tari dan tidak akan terjadi tanpa adanya kemajuan bidang media baru yang berbasis internet. Imajitari Dance Film Festival 2020 pada penyelenggaraannya ditahun ketiga ini selain kategori umum juga membuat kategori film/video dance berdurasi maksimal satu menit untuk konsumsi media sosial khususnya instagram. Hal ini merupakan sebuah upaya merespon berkembangnya media sosial saat ini. Festival juga ingin meraih target penonton sebanyak-banyaknya dengan beragam platform distribusi karya, termasuk melalui media daring yang tanpa perlu menghadirkan penonton di sebuah ruang pemutaran bersama.

Hari ini, berkat perkembangan teknologi, hibridasi antara seni film dan tari tidak hanya menciptakan satu bentuk ekspresi seni yaitu film tari, tetapi juga menunjukkan eksistensi pada bentuk-bentuk ekspresi seni yang lain. Film dan tari hadir dalam karya instalasi dan karya-karya seni media baru lainnya. Dalam gelaran Jakarta Biennale 2017, koreografer Yola Yulfianti menciptakan video instalasi berjudul Pasar Senen Kampung Melayu. Karya tersebut berupa video tari yang diproyeksikan ke delapan lapis kain satin berbagai ukuran. Selain Yola, sutradara Garin Nugroho juga hadir dengan karya retropeksi seniman keramik Hendrawan Riyanto. Garin menghadirkan video kanal tunggal dengan menampilkan tarian sebagai pembawa narasi di beberapa bagian film.

\section{SIMPULAN}

Teknologi sinema semakin berkembang dan memudahkan para pembuat film untuk berkarya, sudah seharusnya hal tersebut bisa menjadi penyemangat para pembuat film tari dan koreografer tari untuk berkarya lebih aktif memproduksi film tari. Di Indonesia, film tari seharusnya bisa berkembang lebih pesat, mengingat negara Indonesia adalah negara yang kaya akan potensi seni tari, khususnya tarian tradisional. Keberagaman tari daerah tentunya akan membangun pengkayaan bentuk dan karakter film tari di Indonesia. Belum lagi jika seni tari tersebut dikomunikasikan dengan berbagai media baru, sehingga mampu menciptakan berbagai bentuk ekspresi lain. Dengan demikian, dalam forum-forum diskusi nantinya perdebatkan terkait pengertian dan batasan-batasan film tari tentu tidak perlu berulang, karena film tari sudah menjadi bagian dari seni film, tari dan media baru.

\section{DAFTAR RUJUKAN}

Ardianto, Deny Tri, 2014. Risang Tetuka; Adaptasi Lakon Gathutkaca Lahir ke Dalam Film Tari. Disertasi Program Doktoral Pengkajian dan Penciptaan Seni, PPs ISI Yogyakarta

Brannigan, Erin. 2006. Yvonne Rainer's memoir "Feelings Are Facts: A Life”. MIT Press published.

Croteau and Hoynes (2003) Media Society: Industries, Images and Audiences (third edition) Pine Forge Press: Thousand Oakes.

Indriasari, Lusiana, 2012. Diakses pada 10 Oktober 2017 pukul 22.00 WIB, pada laman:http://entertainment.kompas.com/read/2012/06/05/21363642/idf.perkenalkan.konsep.film.tari

Mitoma, Judy. 2002. Envisioning Dance on Film and Video, Great Britain: Routledge.

Moleong, Lexy J. 2005. Metodologi Penelitian Kualitatif, Bandung: Remaja Rosdakarya.

Rosenberg, Douglas. 2001. Essay on Screen Dance. Dipresentasikan dalam seminar/simposium Dance for The Camera di Madison, Wiscosin, USA.

Rousseve, David. 2012. "Dance Film and Dance for the Camera." E-mail untuk Deny Tri Ardianto. 12 Februari 2012.

Sukmadinata, Nana Syaodih. 2010. Metode Penelitian Pendidikan. Bandung: PT Remaja Rosdakarya.

Venza, Jac. 2002. Dance as Television: A Continuing Challege. Editor. Judy Mitoma. Envisioning Dance on Film and Video, Great Britain: Routledge.

Wolff, Jessica. 2005. Yvonne Rainer - Director. Diakses pada 11 Januari 2014 pukul 21.00WIB, pada laman: http:// www.filmreference.com/Directors-Pe-Ri/Rainer-Yvonne. html 